\title{
New Method for Evaluating the Visibility of Coronary Stents
}

\author{
János Dobránszky ${ }^{1}$, György Ring ${ }^{2}$, Eszter Bognár ${ }^{3}$, \\ Róbert Kovács ${ }^{4}$, Enikő Bitay ${ }^{5}$
}

${ }^{1}$ MTA-BME Research Group for Composite Science and Technology, Müegyetem rakpart 3, H-1111 Budapest, Hungary

dobranszky.janos@eik.bme.hu

2 BME Faculty of Mechanical Engineering, Department of Materials Science and Engineering, Müegyetem rakpart 3, H-1111 Budapest, Hungary

dobi@eik.bme.hu

${ }^{3}$ BME Faculty of Mechanical Engineering, Department of Materials Science and Engineering, Müegyetem rakpart 3, H-1111 Budapest, Hungary, eszter@eik.bme.hu

${ }^{4}$ BME Department of Electronics Technology, Müegyetem rakpart 3, H-1111 Budapest, Hungary, kovacs@ ett.bme.hu

${ }^{5}$ Sapientia Hungarian University of Transylvania,

Târgu-Mureş - Corunca, Aleea Sighişoarei 1C. Romania, bitay.eniko@eme.ro

Hommage à professor László Gillemot, the first engineer who applied X-ray in the Hungarian industry.

\begin{abstract}
In invasive radiology, $X$-ray imaging is used in both tracking the delivery system and assisting in correct positioning of stents. Until now there has been no objective and quantitative scale of $X$-ray visibility which is also known as radiopacity. There is a clear need from the part of interventional cardiologists for a quantitative in vitro evaluation method with which X-ray visibility can be graded repeatably, objectively, in a validated form across a wide range of fields. Therefore the development of the presented quantitative evaluation approach was decided in order to unambiguously classify the radiopacity of given cardiovascular implants under given in vitro imaging conditions. In this work the relative $X$-ray visibility index $\left(X V_{R}\right)$, which expresses the visibility of the stent compared to the background and the method for determining the value of this index, is introduced. The $X V_{R}$ index is related to a simple quantification method based on image analysis of $X$-ray images of stents. Nevertheless, this stent radiopacity quantification method can also be used in a wide range of clinical contexts.
\end{abstract}

Keywords: stent; visibility; radiopacity; $X$-ray microscopy; image analysis 


\section{Introduction}

Invasive coronary angiography and percutaneous coronary angioplasty are the most important clinical processes for the assessment and therapy of coronary artery stenoses. In the revascularization process a high-resolution X-ray fluoroscope helps the interventional cardiologists to control the position of the stent. As biomedical product, stents have many important and strictly evaluated technical characteristics which form the basis of their comparison when choosing in the market. For these reasons the X-ray visibility is one of the most important functional properties of the stents $[1,2,3]$.

Satisfactory X-ray visibility - which property is often called as "radiopacity" and sometimes as "radiovisibility" [4] or "radiodensity" - relies on a certain level of $\mathrm{X}$-ray attenuation caused by the material of the stent. As a simple definition, radiopacity of a medical device or implant is the ability to absorb X-rays or reduce their permeation [5]. The attribute "radiopaque" is used to describe the ability of a substance to absorb X-rays and appear opaque (white) on radiographs [6]. Without a satisfactory visibility, the interventional cardiologists cannot oversee the location of the stent and its positioning into the stenosed artery precisely on the display of $\mathrm{X}$-ray fluoroscope.

Whereas a standard exists [7] proposing a method for determination of the visibility of catheters, the ISO 25539-2:2008 standard [8] for vascular stents does not specify the precise test protocol. Because of this, assessment tests for classifying the visibility are carried out in numerous ways, but both stent producers and endusers use nowadays generally a subjective classification such as "good", "very good", "excellent", "average", "poor", "low", "high", etc. [9, 10]. An often used method is to characterize X-ray images by their average greyscale level on a 256 level scale. A stent or stent system is evaluated by the difference between the greyscale value of the stent and that of the surrounding area in the picture. [11, 12]. Another evaluation of stents or stent markers is possible by using a "graphic depiction" of marking on the radiograph [13] even more automatically in the fluoroscopy images $[14,15]$.

Elements that have high density and high atomic number, such as $\mathrm{Pt}, \mathrm{Ir}, \mathrm{Ta}, \mathrm{Nb}$, $\mathrm{Pd}, \mathrm{W}$, Mo strongly enhance the radiopacity compared to $\mathrm{Fe}, \mathrm{Cr}, \mathrm{Ni}, \mathrm{Co}$. This effect is used for example in case of Taxus Element Stent (37Fe-33Pt-18Cr-9Ni$2,6 \mathrm{Mo}$ ), whiches thinner struts do not cause a reduction in stent visibility. Similarly, an excellent radiographic visibility characterizes the Wallstent; it consists of round wire struts of $\mathrm{Co}-\mathrm{Cr}$ alloy but the composite wire has an inner core of $\mathrm{Pt}$ [16].

Comparing titanium, Ti-50Ta, Ti-45Ta-5Ir [17] and Nb-based alloys [18, 19] were found much more radiopaque. The producer of the ZoMaxx Stent developed a layered composite, in which the inner tantalum layer significantly improves radiopacity of the thin stent struts [20]. In order to improve the radiopacity the ends 
of some stents are coated with gold markers [21] and dysprosium markers for visualizing the catheters [22].

There are many other works in which the authors evaluate the visibility of stents produced of Nitinol [23, 24, 25, 26], Co-Cr, Co-Pt, 316L [27, 28] and magnesium [29] but not having a clear quantitative method, the results remain inaccurate.

Some research is based on multi-slice computer tomography [30, 31]. The aim of these studies in the beginning was to investigate the stent expansion process, [32] afterwards to define the "stent lumen visibility" at in vitro conditions [33] or after the insertion of the stent $[34,35,36,37,38]$. CT scans were valued on a four or five-degree scale from "excellent" to "not gradable", etc. [39]. The drawback of this type of classification is that removal of subjective elements from the evaluation is not possible.

More different interpretations of term visibility have appeared applied in connection with invasive radiology: "stent visibility rate" was defined as the proportion of visible and the total length of the stent at the CT imaging [40], and "visibilityindex" was generated from geometric data coming from quantitative coronary analysis (QCA) and IVUS-data [41]. A formula was described to provide a quantitative measure of the contrast between an object and the surrounding background. Different aspects of the imaging of a coronary stent were analyzed and it was stated that the general condition for X-ray visibility an object must fulfill, is to provide a level of contrast within the area where it is projected which is sufficient to be detected above the noise level of the image [42]. All these above summarized research could not result in such method, neither for the producers and nor for the end-users, which makes quantitative determination of stent visibility possible similarly to other functional parameters of stents (i.e. recoil, radial strength, metallic surface area, etc.).

There is a clear need for a quantitative evaluation method to grade X-ray visibility of stents, and to compare the different types quantitatively. It should be easily replicable, defined on an objective numerical scale, usable in a wide range of fields, and standardized to the point where it can be routinely applied in measuring X-ray visibility. The objective of this work was the elaboration of an in vitro method which meets each of the following conditions among the needs: objectively characterizes X-ray visibility, gives a quantitative result and permits comparing different sizes, materials and types of stents.

\section{Method for Imaging the Stent}

The new in vitro method for quantification of the visibility will be presented in the followings through the example of two coronary stents. One of them is a CoStar $(2.5 \times 18 \mathrm{~mm})$ stent, the other one is a PRO-Kinetic $(3.0 \times 15 \mathrm{~mm})$ stent; both are made of ASTM F 90 standard specified L-605 type Co-Cr alloy. 
The first step of the in vitro quantification method is to obtain an X-ray microscopy (XRM) image of the stent preferably with the same voltage and cathode heating parameters as in clinical practice. For this a Dage XiDAT XD6600 type X-ray microscope was used. The three test values of cathode heating were 800, 1000 and $1200 \mathrm{~mW}$, but the accelerating voltage was fixed at $90 \mathrm{kV}$ in each case.

Using these X-ray imaging parameters, images were obtained in which the contrast and middle-tone values differ; two XRM images are shown in Fig. 1 taken after balloon expansion of stents. It is also noticeable that in XRM images there are perceptibly different tones at image points in the background.

The X-ray detector renders the cylindrical, lattice-like structure of the implant as a flat projection. The XRM images obtained in this way vary apparently along different imaging parameters applied, or locate the metallic strut of the stent in a random position as Fig. 2 shows. In the nine XRM images the same section of one stent is visible rotated into three distinct random orientations around its axis.

These effects will be discussed in a further paper based on the work of a corresponding $\mathrm{PhD}$ thesis [43], because it is obvious that all different positions and different cathode-heating levels can strongly increase the error of subjective evaluation. Therefore it is needed for a long time to find a solution for the quantitative determination of visibility without errors caused by subjective evaluation.

Apart from the XRM images of the stent, it is necessary for further analysis to have an XRM image of the empty background which image is obtained with absolutely identical parameters.

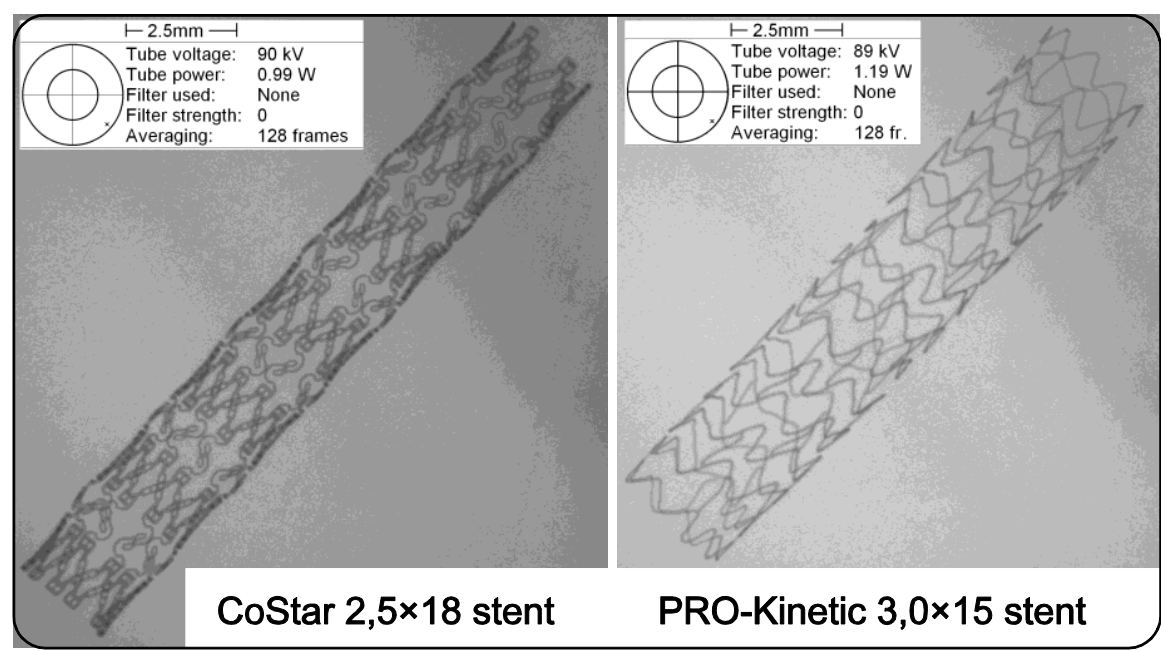

Figure 1

X-ray microscopic image of the examined CoStar stent (a) and PRO-Kinetic stent (b); (as an example; the imaging parameters are intentionally different) 


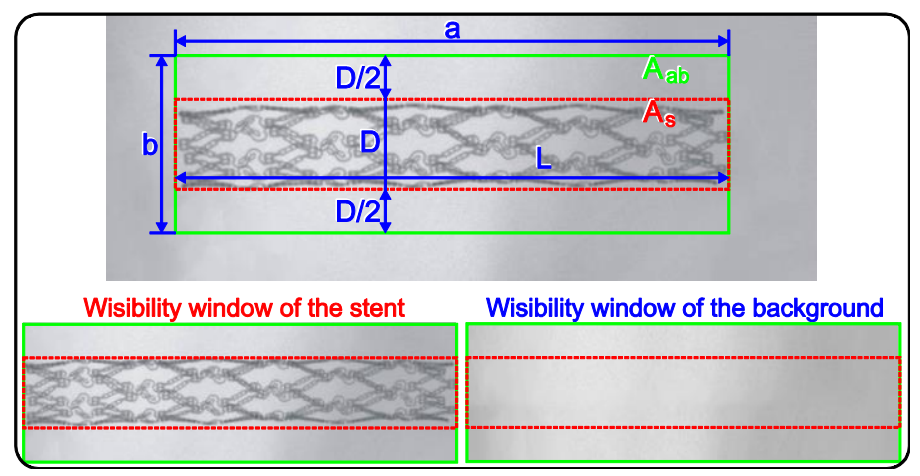

Figure 2

Visibility window on the stent XRM image is defined as the rectangle, which has one side the length of the stent and the other side twice the width (diameter) of the stent; the centred stent is enclosed by the dotted rectangle; these image were taken at $90 \mathrm{kV}$ tube voltage and $1200 \mathrm{~mW}$ cathode heating

\section{Method for Evaluating the XRM Images}

In order to overlay the two XRM images - the one with the stent and the other image of only the background - an equally dimensioned and identically positioned so-called visibility window must be defined to line up and match the two images precisely. The image elements in terms of visibility will be interpreted in this window. When setting the dimensions of the visibility window medical experience and to the fact that visibility in every case strongly depends on the surrounding area and background must be taken into consideration. Fig. 3 helps to survey the definition and construction of visibility window for the CoStar stent.

The visibility window is defined by sides $a$ and $b$ hence for the area $A_{a b}$ equations (1), (2), and (3) have the following values:

$a=L$

$b=D+2 \frac{D}{2}$

$2 A_{S} \cong A_{a b}$

where $L$ is the length and $D$ is the diameter of the stent in its expanded state, $A_{S}$ is the surrounded area of the projection of the stent, and $A_{a b}$ is the area of the visibility window. In the next step the visibility windows must be analyzed as an 8bit, grayscale image since this is the picture format the interventional cardiologists see in practice. 


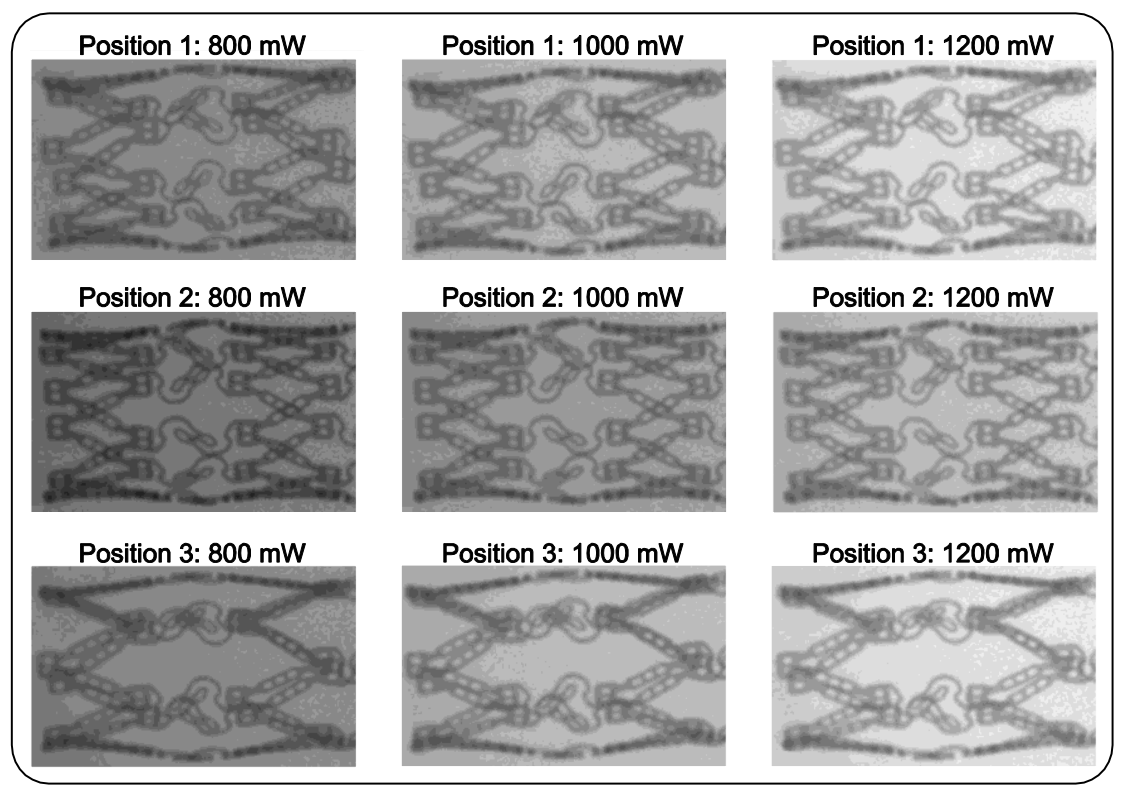

Figure 3

XRM images of two rings of a complete CoStar stent in three random rotated orientations, and three levels of cathode heating (at $90 \mathrm{kV}$ tube voltages)

\section{Results: Properties of the Visibility Windows}

In the interests of defining a quantitative visibility parameter the distribution of number of pixels $(\mathrm{N})$ of the visibility window must be analyzed according to the grayscale level $(\mathrm{G})$. The values $\mathrm{G}=0$ and $\mathrm{G}=255$ correspond to the black and white color respectively. Fig. 4 and Fig. 5 show the grayscale histograms of visibility windows; that for the data points when the image contains the stent, $N_{S}(G)$, and that for the data points when the image does not contain it, $N_{B}(G)$.

The grayscale histogram of the stent-containing visibility window always shows a large interval in the dark pixels' region; the dark pixels' interval $G<G_{B_{M I N}}$ is started at the darkest point of the background's grayscale histogram $\left(G_{B_{M I N}}=\right.$ 168 in Fig. 4 and Fig. 5). The area under the curve is proportional to the X-ray absorption of the stent, thus to the visibility, so it would be practical to define a visibility parameter which clearly reflects this simple regularity. Moreover, similar grey-scale image based segmentation method was elaborated for analysis of the captured images of printed, folded-gathered substrates or spectrograms [44, 45]. 


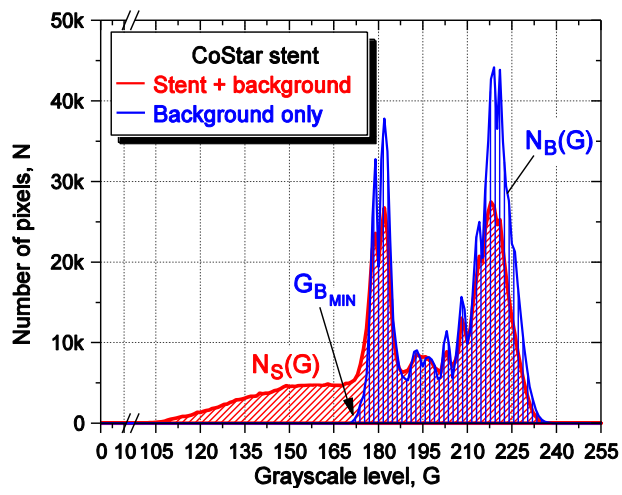

Figure 4

Grayscale histograms (distribution of the pixels) of XRM images of the visibility windows for CoStar stent

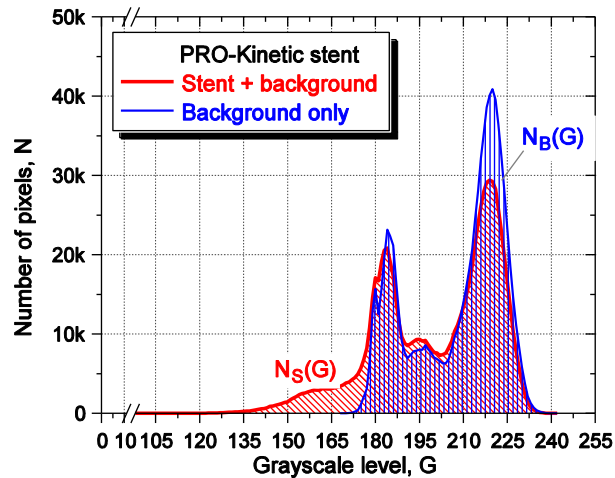

Figure 5

X-ray microscopic image of the examined CoStar stent (a) and PRO-Kinetic stent (b)

Let $U_{S}(G)$ and $U_{B}(G)$ be the visibility functions obtained by integration of the histogram of the stent containing and the empty visibility window, $N_{S}(G)$ and $N_{B}(G)$. The integrals of the grayscale histograms match the shaded areas under the two respective curves. The two integrals are given in equations (4) and (5), and the integral functions for the two examined stents are shown in Fig. 6 and Fig. 7.

$$
\begin{aligned}
& U_{\mathrm{S}}(G)=\int_{G_{L}}^{G_{H}} N_{\mathrm{S}}(G) \mathrm{d} G \\
& U_{\mathrm{B}}(G)=\int_{G_{L}}^{G_{H}} N_{\mathrm{B}}(G) \mathrm{d} G
\end{aligned}
$$


Where $N_{S}(G)$ is the grayscale histogram function of the visibility window containing the stent, $N_{B}(G)$ is the same of the background. $U_{S}(G)$ and $U_{B}(G)$ respectively are the two integrals, so-called visibility functions. The limits $G_{L}=0$ and $G_{H}=255$ are the respective boundary conditions, according to the extreme values of grayscale level.

In the first developing phase of this visibility quantification method, the grayscale histograms were produced by using the image analyzer software, Image-Pro Plus, and the numerical integrations were carried out by using the software Microcal Origin. Parallel to the validation, improvement and large-scale application of this method, customized software was also developed which ensures to evaluate even a huge number of XRM images easily and quickly.

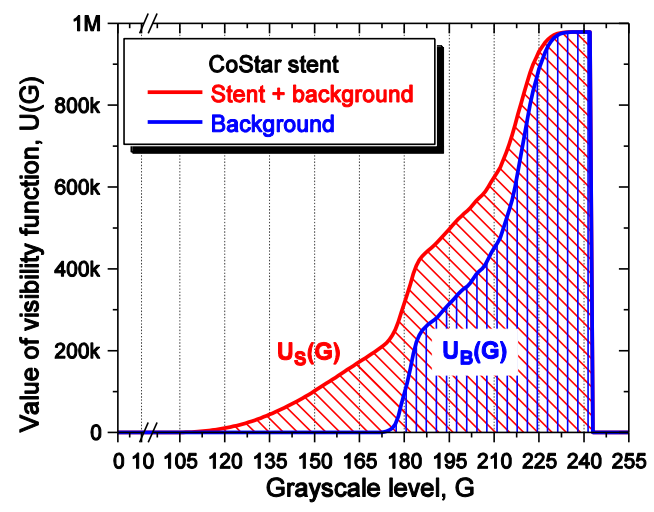

Figure 6

Visibility functions and areas under the curve of the stent-containing and the wide visibility window for CoStar stent

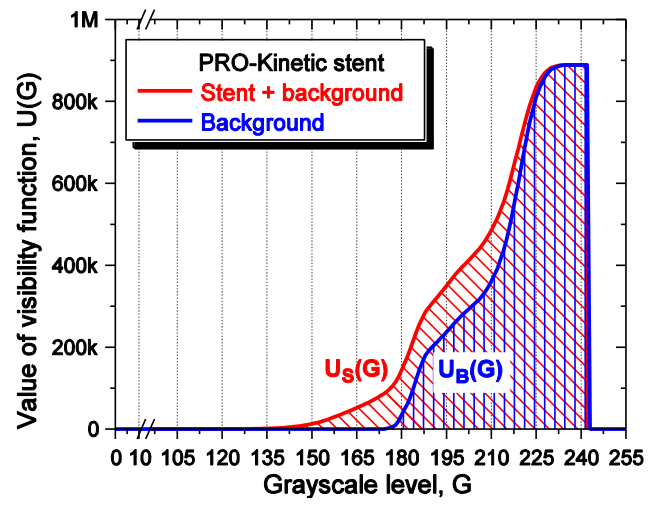

Figure 7

Visibility functions and areas under the curve of the stent-containing and the wide visibility window for PRO-Kinetic stent 


\section{Discussion: Computing the X-Ray Visibility}

Figure 6 shows the two visibility functions: one for data from the visibility window containing only the background (empty), the other for data from the visibility window containing the background and the stent. The two visibility windows contain some image points with identical numerical values, and in fact the maximums of the two visibility functions are necessarily identical.

As a dimensionless index, let us introduce, the relative $X$-ray visibility index, $X V_{R}$, which expresses the visibility of the stent in comparison to the background within the visibility window. This is a proportional measure expressing the visibility of the stent as a percentage of the visibility of the background. From the ratio between the areas under the curve of the two visibility functions, the relative visibility index, $X V_{R}$, is defined by the following equation (6):

$$
X V_{R}=\left(\frac{\int_{G_{L}}^{G_{H}} U_{\mathrm{S}}(G) \mathrm{d} G}{\int_{G_{L}}^{G_{H}} U_{\mathrm{B}}(G) \mathrm{d} G}-1\right)=\left(\frac{\iint_{G_{L}}^{G_{H}} N_{\mathrm{S}}(G) \mathrm{d} G}{\iint_{G_{L}}^{G_{H}} N_{\mathrm{B}}(G) \mathrm{d} G}-1\right)=\left(\frac{\psi_{S}}{\psi_{B}}-1\right)
$$

where $\psi_{S}$ and $\psi_{B}$ express the visibility number, respectively for the stent containing and for the empty visibility window, on the basis of the 8-bit, grayscale XRM image. Equation (6) above derives these two terms from an expression for the double integral of the grayscale histogram of the XRM image.

The $X V_{R}$ index defined this way characterizes the $\mathrm{X}$-ray visibility of the stent itself under given $X$-ray microscopy imaging conditions. This parameter is suitable for quantitative evaluation and comparison of the visibility of different stents which differ in type, material, diameter or length - in which identical scanning conditions must be ensured. For the two stents which were shown as examples, the following $\mathrm{XV}_{\mathrm{R}}$ values were determined: $29.52 \%$ for the CoStar stent, and $20.15 \%$ for the PRO-Kinetic stent.

Between identical scanning conditions the relative visibility index excellently describes even quite small differences in visibility. In place of subjective evaluations or scales used earlier, a quantitative method and parameter which accurately ranks subtle deviations was developed based on objective measurements.

\section{Conclusions}

In the course of this study, a new in vitro method of measurement for the characterization of visibility (radiopacity) of stents was elaborated which objectively describes X-ray visibility providing quantitative results suitable for comparison of stents or catheters, guide-wires, markers and other cardiovascular devices. This objective, numerical index is suitable for routine use in evaluating radiopacity, as an in vitro method. 
In clinical practice the elaborated method is suitable for assessing visibility parameters using 8-bit, grayscale X-ray microscopy (XRM) images.

The relative $X$-ray visibility index, $X V_{R}$, which characterizes the stent radiopacity under given $X$-ray microscopy conditions was introduced. This index is very effective for quantitative evaluation of the visibility of different stents - which differ in type, material, diameter or length - when identical scanning conditions are ensured.

Moreover, the principle and the calculation method of the relative X-ray visibility index are easily adaptable for the quantitative evaluation of X-ray angiograms and their improving algorithms.

Instead of the previously mentioned subjective evaluations or scales, the elaborated method has defined a quantitative feature which is based on objective data; consequently it permits precise ranking of subtle deviations.

\section{Acknowledgements}

This research was supported by the European Union and the State of Hungary, cofinanced by the European Social Fund in the framework of TÁMOP 4.2.4. A/-111-2012-0001 'National Excellence Program'.

\section{References}

[1] Serruys PW (1997) Handbook of Coronary Stents. Martin Dunitz, London

[2] Serruys PW, Kutryk MJB, Ong ATL (2006) Coronary-Artery Stents. N Engl J Med. DOI: 10.1056/NEJMra051091

[3] Kutryk MJB, Serruys PW (1998) Coronary Stenting. Informa Healthcare, London

[4] Briguori C, Sarais C, Pagnotta P, Liistro F, Montorfano M, Chieffo A, Sgura F, Corvaja N, Albiero R, Stankovic G, Toutoutzas C, Bonizzoni E, Di Mario C, Colombo C (2002) In-Stent Restenosis in Small Coronary Arteries. Impact of Strut Thickness. J Am Coll Cardiol.

DOI: 10.1016/S0735-1097(02)01989-7

[5] Mosby's Medical Dictionary, $8^{\text {th }}$ edition (2009) Elsevier

[6] Hunter TB, Taljanovic MS (2003) Glossary of Medical Devices and Procedures: Abbreviations, Acronyms, and Definitions. RadioGraphics.

DOI: $10.1148 / \mathrm{rg} .231025136$

[7] Standard No. DIN 13273-7:2003-08; Catheters for Medical Use, Part 7, Determination of the X-Ray Attenuation of Catheters; Requirements and Testing (2003)

[8] Standard No. ISO 25539-2:2008; Cardiovascular Implants - Endovascular Devices - Part 2: Vascular Stents (2008) 
[9] Wiskirchen J, Kraemer K, König C, Kramer U, Trübenbach J, Wersebe A, Tepe G, Dietz K, Claussen C, Duda S (2004) Radiopacity of Current Endovascular Stents: Evaluation in a Multiple Reader Phantom Study. J Vasc Intervent Radiol. DOI: 10.1097/01.RVI.0000136985.06722.AD

[10] Chan WA, Bini TB, Venkatraman SS, Boey FYC (2006) Effect of Radioopaque Filler on Biodegradable Stent Properties. J Biomed Mater Res A. DOI: $10.1002 /$ jbm.a.30714

[11] Duda S, Wiskirchen J, Tepe G, Bitzer M, Kaulich TW, Stoeckel D, Claussen DC (2000) Physical Properties of Endovascular Stents: an Experimental Comparison. J Vasc Intervent Radiol 11:645-654.

DOI: $10.1016 / \mathrm{S} 1051-0443(07) 61620-0$

[12] Dyet JF, Watts WG, Ettles DF, Nicholson AA (2000) Mechanical Properties of Metallic Stents: How do These Properties Influence the Choice of Stent for Specific Lesions? Cardiovasc lntervent Radiol 23:47-54.

DOI: $10.1007 / \mathrm{s} 002709910007$

[13] Miura S, Yoshioka T, Furuichi K, Tanaka T, Kichikawa K, Ohishi H (2003) Mechanical Properties of Biliary Metallic Stents: an Experimental Comparison. Nippon Acta Radiologica, 63:201-209. PMID: 12822444

[14] Courboulay V, Ménard M, Eboueya M, Courtellemont P, Vaillant R, Coisne D (2002) A Fuzzy Multi-Local Method to Detect Specific Shapes. In: FUZZ-IEEE'02. Proceedings of the 2002 IEEE International Conference on Fuzzy Systems, Université de La Rochelle, pp. 2:920-925

[15] Courboulay V, Desfieux J, Ménard M, Eboueya M, Courtellemont P, Vaillant R, Coisne D (2003) Localisation et détection de stents sur des images rayons-X bas contraste. Stent detection and localisation on low contrast X-ray images. ITBM-RBM 24:28-43.

DOI: $10.1016 / \mathrm{S} 1297-9562(03) 00004-4$

[16] von Birgelen C, Airiian SG, de Feyter PJ, Foley DP, van der Giessen WJ, Serruys PW (1998) Coronary Wallstents Show Significant Late, Postprocedural Expansion Despite Implantation with Adjunct High-Pressure Balloon Inflations. Am J Cardiol 82(2):129-134.

PII: S0002-9149(98)00317-8

[17] O'Brien B, Stinson J, Carroll W (2008) Initial Exploration of Ti-Ta, TiTa-Ir and Ti-Ir alloys: Candidate Materials for Coronary Stents. Acta Biomaterialia 4:1553-1559. DOI:

http://dx.doi.org/10.1016/j.actbio.2008.03.002

[18] Beier F, Gyöngyösi M, Raeder T, v. Eckardstein-Thumb E, Sperker W, Albrecht P, Spes C, Glogar D, Mudra H (2006) First In-Human Randomized Comparison of an Anodized Niobium Stent Versus a Standard Stainless Steel Stent. An Intravascular Ultrasound and Angiographic Two-Center 
Study: The VELA Study. Clin Res Cardiol 95:455-460.

DOI: $10.1007 / \mathrm{s} 00392-006-0406-7$

[19] O'Brien B, Stinson J, Carroll W (2008) Development of a New Niobiumbased Alloy for Vascular Stent Applications. J Mech Behav Biomed Mater 1:303-312. DOI: 10.1016/j.jmbbm.2007.11.003

[20] Abizaid A, Lansky AJ, Fitzgerald PJ, Tanajura LF, Feres F, Staico R, Mattos L, Abizaid A, Chaves A, Centemero M, Sousa AGMR, Sousa JE, Zaugg MJ, Schwartz LB (2007) Percutaneous Coronary Revascularization Using a Trilayer Metal Phosphorylcholine-coated Zotarolimus-Eluting Stent. Am J Cardiol 99:1403-1408. doi:10.1016/j.amjcard.2006.12.064

[21] Biehl V, Wack T, Winter S, Seyfert UT, Breme J (2002) Evaluation of the Haemocompatibility of Titanium-based Biomaterials. Biomolecular Engineering 19:97-101. DOI:http://dx.doi.org/10.1016/j.bbr.2011.03.031

[22] Saeed M, Hetts SW, English J, Wilson M (2012) MR Fluoroscopy in Vascular and Cardiac Interventions (review). Int J Cardiovasc Imaging 28:117137. DOI: $10.1007 / \mathrm{s} 10554-010-9774-1$

[23] Nelson BD (2001) Expandable Metal Stents: Physical Properties and Tissue Responses. Techniques in Gastrointestinal Endoscopy 3:70-74.

DOI: $10.1053 /$ tgie.2001.22152

[24] Cheng Y, Cai W, Li HT, Zheng YF (2006) Surface Modification of NiTi Alloy with Tantalum to Improve its Biocompatibility and Radiopacity. J Mater Sci 41(15):4961-4964. DOI: 10.1007/s10853-006-0096-6

[25] Gutiérrez-Chico JL, Serruys PW, Girasis C, Garg S, Onuma Y, Brugaletta S, García-García H, van Es G-A, Regar E (2012) Quantitative MultiModality Imaging Analysis of a Fully Bioresorbable Stent: a Head-to-Head Comparison between QCA, IVUS and OCT. Int J Cardiovasc Imaging 28(3):467-478. DOI: 10.1007/s10554-011-9829-y

[26] Steegmüller R, Strobel M, Flaxmeier E, Schuessler A (2006) MicroWelding for Improved Radiopacity of Nitinol-Stents. ADMEDES SchuesslerGmbH. $\quad$ ttp://www.admedes.com/sites/files/admedes/files/MicroWelding_for_Improved_Radiopacity_of_Nitinol-Stents.pdf (2013-06-30)

[27] Kereiakes DJ, Cox DA, Hermiller JB, Midei MG, Bachinsky WB, Nukta ED, Leon MB, Fink S, Marin L, Lansky AJ (2003) Usefulness of a Cobalt Chromium Coronary Stent Alloy. Am J Cardiol 92:463-466.

DOI:10.1016/S0002-9149(03)00669-6

[28] Kereiakes DJ, Cannon LA, Feldman RL, Popma JJ, Magorien R, Whitbourn R, Dauber IM, Rabinowitz AC, Ball MW, Bertolet B, Kabour A, Foster MC, Wang JC, Underwood P, Dawkins KD (2010) Clinical and Angiographic Outcomes after Treatment of de Novo Coronary Stenoses with a Novel Platinum Chromium Thin-Strut Stent. J Am Coll Cardiol 56:264-71. DOI:10.1016/j.jacc.2010.04.011 
[29] Siekmeyer G, Steegmüller R, Schrader B, Hegel A, Strobel M, Schuessler A (2005) Novel Microjoining Techniques to Improve Stent Radiopacity. ADMEDES Schuessler GmbH.

http://www.admedes.com/sites/files/admedes/files/Novel_MicroJoining_Te chniques_to_Improve_Stent_Radiopacity.pdf (2013-06-30)

[30] Cademartiri F, Mollet NR, Runza G, Belgrano M, Malagutti P, Meijboom BW, Midiri M, de Feyter PJ, Krestin GP (2006) Diagnostic Accuracy of Multislice-computed Tomography Coronary Angiography is Improved at Low Heart Rates. The International Journal of Cardiovascular Imaging 22(1):101-105. DOI: 10.1007/s10554-005-9010-6

[31] La Grutta L, Runza G, Galia M, Maffei E, Lo Re G, Grassedonio E, Tedeschi C, Cademartiri F, Midiri M (2012) Atherosclerotic Pattern of Coronary Myocardial Bridging Assessed with CT Coronary Angiography. Int J Cardiovasc Imaging 28(2):405-414. DOI: 10.1007/s10554-011-9817-2

[32] Connolley T, Nash D, Buffiere JY, Sharif F, McHugh PE: X-Ray MicroTomography of a Coronary Stent Deployed in a Model Artery. Medical Engineering \& Physics 29 (2007) 1132-1141.

DOI:10.1016/j.medengphy.2006.10.016

[33] Maintz D, Gride M, Fallenberg EM, Heindel W, Fischbach R (2003) Assessment of Coronary Arterial Stents by Multislice-ct Angiography. Acta Radiologica 44:597-603. DOI:10.1080/02841850312331287719

[34] Kong L, Jin Z, Zhang S, Zhang Z, Wang Y, Song L, Zhang X: Assessment of Coronary Stents by 64-Slice-computed Tomography: In-Stent Lumen Visibility and Patency. Chin Med Sci J. 24 (2009) 156-160. PMID: 19848316

[35] Rist C, Nikolaou K, Flohr T, Wintersperger BJ, Johnson TR, Reiser MF, Becker CR (2006) Ultra-High-Resolution Mode for the Assessment of Coronary Artery Stents - ex vivo Imaging with 64-Slice-computed Tomography. Academic Radiology 13(9):1165-1167.

DOI:10.1016/j.acra.2006.06.006

[36] Ehara M, Kawai M, Surmely J-F, Matsubara T, Terashima M, Tsuchikane E, Kinoshita Y, Ito T, Takeda Y, Nasu K, Tanaka N, Murata A, Fujita H, Sato K, Kodama A, Katoh O, Suzuki T (2007) Diagnostic Accuracy of Coronary In-Stent Restenosis using 64-Slice-computed Tomography: Comparison with Invasive Coronary Angiography. Journal of the American College of Cardiology 49(9):951-959.

DOI: http://dx.doi.org/10.1016/j.jacc.2006.10.065

[37] Das KM, El-Menyar AA, Salam AM, Singh R, Dabdoob WAK, Albinali HA, Suwaidi JA (2007) Contrast-enhanced 64-Section Coronary Multidetector ct Angiography versus Conventional Coronary Angiography for Stent Assessment. Radiology 245(2):424-432.

DOI: 10.1148/radiol.2452061389 
[38] Rist C, Nikolaou K, Flohr T, Wintersperger BJ, Reiser MF, Becker CR (2006) High-Resolution ex vivo Imaging of Coronary Artery Stents using 64-Slice-computed Tomography - Initial Experience. Eur Radiol 16:15641569. DOI: $10.1007 / \mathrm{s} 00330-006-0186-5$

[39] de Heer LM, Habets J, Kluin J, Stella PR, Mali WP, van Herwerden LA, Budde RP (2012) Assessment of a Transcatheter Heart Valve Prosthesis with Multidetector-computed Tomography: in vitro and in vivo Imaging Characteristics. Int J Cardiovas Imag. DOI: 10.1007/s10554-012-0111-8

[40] Clarençon F, Piotin M, Pistocchi S, Babic D, Blanc R (2012) Evaluation of Stent Visibility by Flat Panel Detector CT in Patients Treated for Intracranial Aneurysms. Neuroradiology 54:1121-1125.

DOI: $10.1007 / \mathrm{s} 00234-011-1002-8$

[41] Hagemeister J, Baer FM, Schwinger RHG, Höpp HW (2005) Compliance of a Cobalt Chromium Coronary Stent Alloy - the COVIS Trial. Current Controlled Trials in Cardiovascular Medicine 6:17

DOI: $10.1186 / 1468-6708-6-17$

[42] Schmiedl R, Schaldach M: X-Ray Imaging of Coronary Stents (2000) Progress in Biomedical Research 5(3):184-196. http://progress.biomed.unierlangen.de/documents/200005030184.pdf (Accessed 30 December 2012)

[43] Ring György (2010) Pre-Clinical Evaluation of Coronary Stents and other Endoprotheses. PhD thesis, BME Faculty of Mechanical Engineering

[44] Apró M, Novaković D, Pál Sz, Dedijer S, Milić N (2013) Colour Space Selection for Entropy-based Image Segmentation of Folded Substrate Images. Acta Polytechnica Hungarica 10(1):43-62.

DOI: 10.12700/APH.10.01.2013.1.3.

[45] Perović A, Đorđević Z, Paskota M, Takači A, Jovanović A (2013) Automatic Recognition of Features in Spectrograms Based on some Image Analysis Methods. Acta Polytechnica Hungarica 10(2):153-172.

DOI: 10.12700/APH.10.02.2013.2.11 